\title{
CFD Modeling of Atmospheric Boundary Layer Simulations in Wind Tunnels
}

\author{
Ahmed ABUBAKER, Ivan KOSTIĆ, Olivera KOSTIĆ, Zoran STEFANOVIĆ
}

\begin{abstract}
Wind tunnel tests of wind influence on ground objects require proper experimental modeling of the atmospheric boundary layer (ABL). The authors have performed computational analyses with an aim to establish a reliable computational algorithm that could resemble complex flow patterns in wind tunnels with various obstacles, used to simulate appropriate velocity profiles within the ABL. For experimental verifications, measurements from two experimental facilities were applied, with speeds ranging from $1-4 \mathrm{~m} / \mathrm{s}$ in the first, and $45 \mathrm{~m} / \mathrm{s}$ in the second. For all considered cases, good agreements between the measured and computed speed profiles for operational engineering purposes have been achieved. In the sense of qualitative analyses, calculated contours of velocity magnitude and eddy viscosity inside the wind tunnel test sections have verified that good homogeneity of the simulated $A B L$ in both wind tunnels had been established in the domains where velocity profiles were measured. Presented results have shown the capability of here established calculation model to resemble a number of costly wind tunnel test hours during preparations of proper obstacle arrangements for experimental ABL modeling in a wide wind speed range, and thus reduce the overall project costs. Also, presented CFD algorithm can readily be calibrated and used for engineering research of wind effects on different ground objects, as a virtual wind tunnel.
\end{abstract}

Keywords: atmospheric boundary layer; SST k-w turbulent model; subsonic wind tunnel; velocity profile

\section{INTRODUCTION}

The wind tunnels have been applied for many years as valuable tools for studying many different air flow characteristics not only in the aviation, but in other engineering fields as well [1]. Investigations of atmospheric aerodynamic phenomena in wind tunnels are based on the adequate modeling of the atmospheric boundary layer (ABL), with the purpose of obtaining better understanding of complex airflow behavior associated with it [2]. The use of wind tunnels: (1) enables proper control of the flow parameters, based on the required accuracy and economy of the tests, (2) enables modeling of the actual environment in proper scale, and (3) obtains data bases of results that can be used for the calibration and verification of the Computational Fluid Dynamics (CFD) calculations.

Development of the CFD calculation models that can be used for reliable atmospheric boundary layer analyses is of high importance. CFD can be used to study many processes and phenomena in the ABL, and the accuracy of the calculations is crucial factor that makes it a contemporary tool that can be used equally well as the experimental facilities. Several comparative studies between CFD and wind tunnel or environmental measurements have been accomplished so far, e.g. [3-6]. In them, the reason for certain differences in results was addressed to the application of the Reynolds Averaged Navier Stokes (RANS) solution of the CFD simulations that were used for modeling of the dispersion processes in experimental facilities or real environment measurements. On the other hand, the RANS based calculations are a reasonable compromise in the sense of the rational use of computer resources, combined with the adequate turbulence model. The standard $k-\varepsilon$ turbulence model has extensively been used in many simulations of the ABL, in conjunction with the available boundary conditions and meteorological parameters [7-12]. Another "two equation" model - the $k-\omega$ model, where the transport equations utilize the turbulent kinetic energy $(k)$ and the specific dissipation rate $(\omega)$, has been reported to perform much better than $k-\varepsilon$ models in case of adverse pressure gradients, but is very sensitive to the assigned inlet conditions [13-
15]. A model that combines advantages of the $k-\varepsilon$ and $k-\omega$ approaches is the shear stress transport SST $k$ - $\omega$ model, where the $k$ - $\omega$ model is applied near the surface, and the $k$ $\varepsilon$ model is used in the free shear layers; advantages in ABL modeling are shown in [16].

The computations presented in this work have been verified by measurements performed at the Assiut University (Fig. 1), and at the University of Belgrade, Faculty of Mechanical Engineering (Fig. 2). In both wind tunnels the atmospheric boundary layer (ABL) has been simulated. Those tests, and obtained experimental data, are discussed in [17] and [18]. These experiments were performed with several different types of obstacle devices, simulating actual ground obstacle influences.

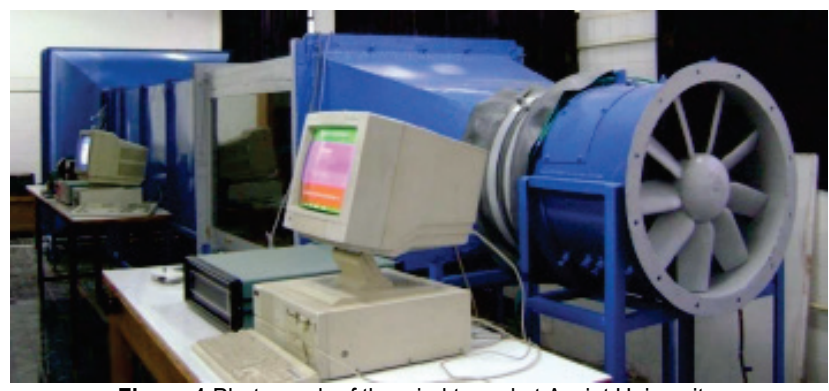

Figure 1 Photograph of the wind tunnel at Assiut University

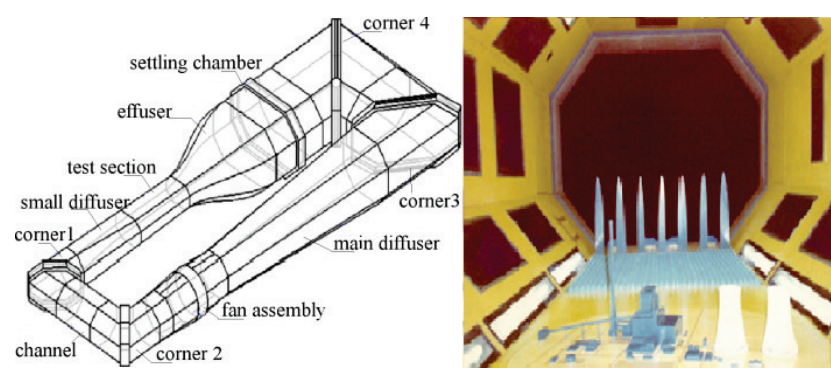

Figure 2 A schematic view of the wind tunnel at Belgrade University, and photograph of its test section

The aim of the paper was to establish a computational model that would be able to perform adequate numerical simulations of the selected experimental conditions and setups, and which would provide a possibility to widen the numerical investigations to other possible devices, forms 
and shapes aimed for the simulations of the ABL, without repeating costly tunnel tests runs. For that purpose it was necessary to define the adequate meshing and calculation options that can provide good agreements with the available experimental data, both qualitatively and quantitatively.

Here presented CFD simulations have been done using the $k$ - $\omega S S T$ model, and were performed for different flow speeds (both low and high), applied in two wind tunnel test sections, with the same models and obstacles as used in actual tests. Obtained agreements for velocity profiles for all speeds were very good for the purpose of operational engineering applications. Numerical results have also provided deeper qualitative insights in flow-field characteristics during both experiments, than those published from actual tests.

\section{THEORETICAL FORMULATION}

The SST $k$ - $\omega$ model is defined by the following equations, with several modifications added [19-24]:

$\frac{\partial}{\partial t}(\rho k)+\frac{\partial}{\partial x_{i}}\left(\rho k u_{i}\right)=$

$=\tilde{P}_{k}-\beta^{*} \rho k \omega+\frac{\partial}{\partial x_{j}}\left(\left(\mu+\sigma_{k} \mu_{t}\right) \frac{\partial k}{\partial x_{i}}\right)$,

$\frac{\partial}{\partial t}(\rho \omega)+\frac{\partial}{\partial x_{i}}\left(\rho \omega u_{i}\right)=\alpha \rho S^{2}+\frac{\partial}{\partial x_{i}}\left(\left(\mu+\sigma_{k} \mu_{t}\right) \frac{\partial \omega}{\partial x_{i}}\right)+$

$+2\left(1-F_{1}\right) \rho \sigma_{\omega 2} \frac{1}{\omega} \frac{\partial k}{\partial x_{i}} \frac{\partial \omega}{\partial x_{i}}-\beta \rho \omega^{2}$,

where blending function $F_{1}$ is:

$$
\begin{aligned}
& F_{1}=\tanh \left\{\left\{\min \left[\max \left(\frac{\sqrt{k}}{\beta^{*} \omega y} \frac{500 v}{y^{2} \omega}\right) \frac{4 \rho \sigma_{\omega 2} k}{C D_{k \omega} y^{2}}\right]\right\}^{4}\right\}, \\
& C D_{k \omega}=\max \left(2 \rho \sigma_{\omega 2} \frac{1}{\omega} \frac{\partial k}{\partial x_{i}} \frac{\partial \omega}{\partial x_{i}} 10^{-10}\right)
\end{aligned}
$$

and $y$ represents the distance from the closest wall.

Function $F_{1}$ takes the value 0 far from the surface $(k-\varepsilon$ model), and changes to 1 within the boundary layer ( $k$ $\omega$ model).

Turbulent eddy viscosity is given by the equation:

$$
v_{t}=\frac{a_{1} k}{\max \left(a_{1} \omega S F_{2}\right)}
$$

where $S$ represents the invariant measure of the strain rate, and $F_{2}$ is a second blending function:

$$
F_{2}=\tanh \left[\left[\max \left(\frac{2 \sqrt{k}}{\beta^{*} \omega y} \frac{500 v}{y^{2} \omega}\right)\right]^{2}\right]
$$

In the $k-\omega$ model the production limiter is used to prevent the increase of turbulence in stagnation domains:

$$
P_{k}=\mu_{t} \frac{\partial u_{i}}{\partial x_{j}}\left(\frac{\partial u_{i}}{\partial x_{j}}+\frac{\partial u_{i}}{\partial x_{i}}\right) \rightarrow \tilde{P}_{k}=\min \left(10 P_{k} \beta^{*} \rho k \omega\right)
$$

All constants are calculated by combining the appropriate constants of the $k-\varepsilon$ and the $k-\omega$ model, using $\alpha=\alpha_{1} F+\alpha_{2}(1-F)$ etc. The constants used in this model are: $\beta^{*}=0.09, \alpha_{1}=5 / 9, \beta_{1}=3 / 40, \sigma_{k 1}=0.85, \sigma_{\omega 1}=0.5, \alpha_{2}$ $=0.44, \beta_{2}=0.0828, \sigma_{k 2}=1, \sigma_{\omega 2}=0.856$.

\section{EXPERIMENTAL FACILITIES}

Tests performed in two wind tunnels represent the designs and experimental studies of several passive device arrangements that were utilized to model the atmospheric boundary layer velocity distributions at different flow speeds within their test sections.

\subsection{The Assiut University Wind Tunnel}

This experimental facility was designed and built at the Assiut University, Mechanical Engineering Department, for the environmental studies and research.

This is a subsonic open-loop type tunnel, with speed range up to $4 \mathrm{~m} / \mathrm{s}$. It consists of the following components: an upstream settling section, contraction cone (effuser), air heater, after-heater settling chamber, boundary layer development area, test section, the transition and flexible connecting, and an axial fan (disposition of elements is shown in Fig. 1).

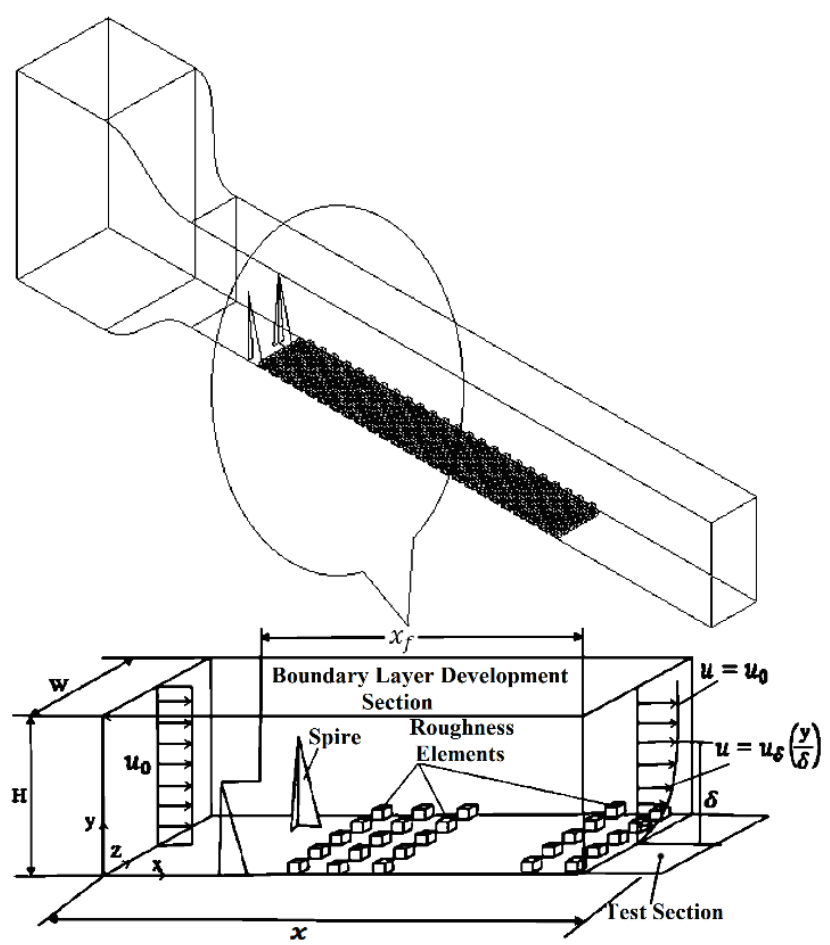

Figure 3 Conceptual models for the contraction cone and boundary layer development section at Assuit University, illustrating spires arrangement, and arrays of roughness elements

Three spires and 710 cubes (or so called - roughness elements) made of wood blocks and boards were positioned and distributed as defined in [17]. They were used to simulate the ground surface conditions and they 
were placed on the floor of the boundary layer development chamber, which is $1 \mathrm{~m}$ high, $1 \mathrm{~m}$ wide and $3.5 \mathrm{~m}$ long (see Fig. 3).

Tests were performed to measure the vertical mean velocity distribution at different heights at the test section entrance.

Experiments have been performed and results gathered for three different setups. The first runs were made with empty wind tunnel. The next set of tests was performed in the wind tunnel with only spires inside. The third set of experiments was done both with the spires and the roughness elements.

\subsection{The Belgrade University Wind Tunnel}

This wind tunnel was designed and constructed at the Aeronautical Institute of the Faculty of Mechanical Engineering, University of Belgrade, both for the aeronautical and the environmental studies and research. It is a subsonic closed-loop type, with speeds ranging up to $60 \mathrm{~m} / \mathrm{s}$, with the power plant used at the time when here presented tests were done. It consists of the upstream settling chamber, effuser, test section, small diffuser, first corner, channel, second corner, the axial flow fan, main diffuser, third corner and fourth corner (see Fig. 2).

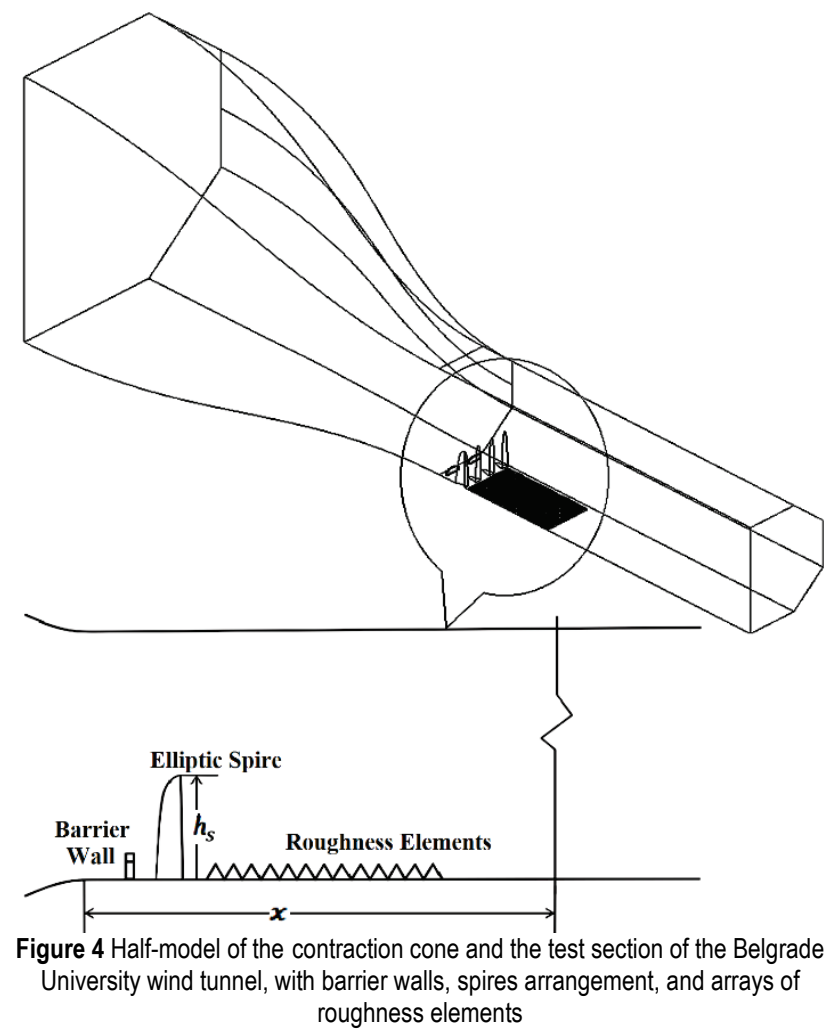

Four front flat plates (barrier walls), seven semielliptic spires and 1156 pyramidal elements (surface roughnesses) were used to simulate the earth surface conditions. They were mounted on the octagonal test section bottom, behind the entrance [18]. The test section of this tunnel is $2 \mathrm{~m}$ high, $2.8 \mathrm{~m}$ wide, and $6 \mathrm{~m}$ long (Fig. 4). Unlike the Assuit University tunnel, this is a general purpose wind tunnel and has no separate boundary layer development section.
Tests here were performed to measure the mean velocity distribution at different vertical positions from the bottom, at the middle of its length ( $3 \mathrm{~m}$ from the inlet).

\section{COMPUTATION METHODOLOGY}

Computations have been performed using 3D analyses in ANSYS Fluent. Half-models for the contraction cones and test sections for both wind tunnels were implemented (see Figs. 3 and 4) in order to achieve proper atmospheric boundary layer simulations, but also to reduce the mesh elements number in the calculation domain, because of the air flow symmetry.

Unstructured meshes have been generated for both wind tunnels. Optimum control volume discretization has been performed, with the aim to locally decrease the size of elements in the specific regions such as the lower wall of test section, sharp and elliptical edges of spires etc., but also to preserve a reasonably low number of nodes and mesh cells, with appreciable quality of the mesh.

Numerical analyses for Assuit University wind tunnel have been done for two cases. Firstly, only spires had been placed on the bottom wall of boundary layer development chamber, and the total number of elements in this unstructured mesh (see Fig. 5(a)) was of the order of 3600000 . In the next case, both cubes and spires have been applied to model the obstacles that form the atmospheric boundary layer. The total number of mesh cells generated this way was approximately 4800000 (Fig. 5(b)).
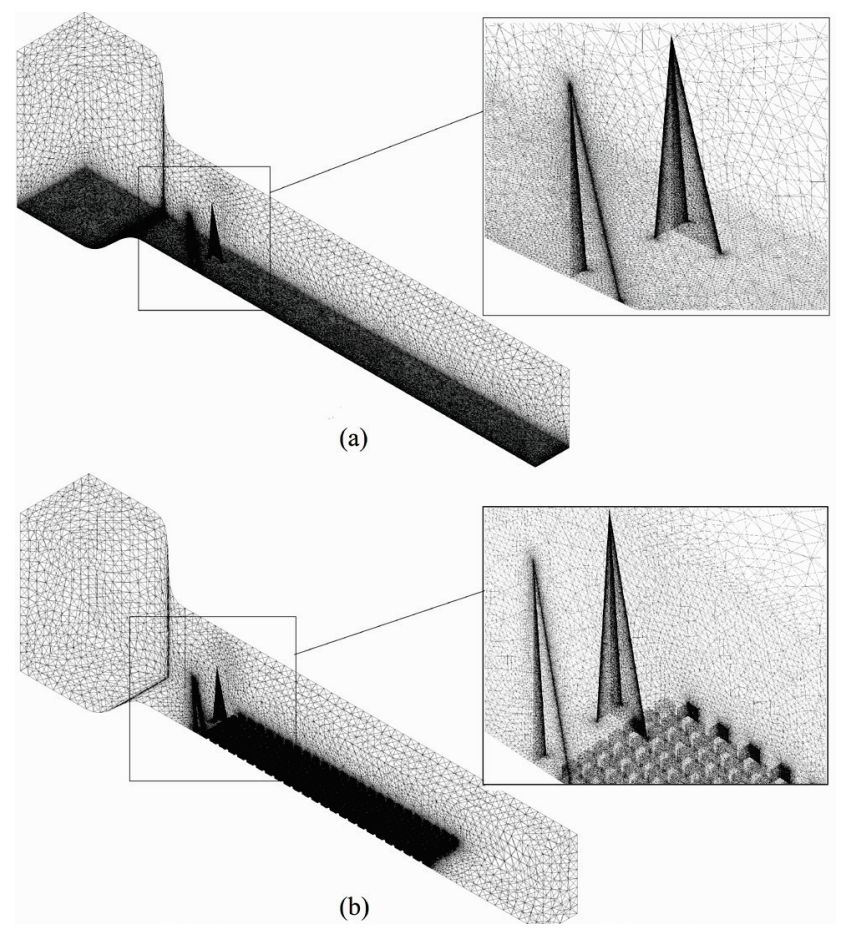

Figure 5 Case (a) - spires only, and case (b) - spires and surface roughness Unstructured meshes for two cases tested at the Assuit University

Numerical analyses for Belgrade University wind tunnel have been done for one case. For those analyses, the wall fences, semi-elliptical spires and small pyramids were placed at the bottom of test section in order to replicate elements that form the actual ABL. The total number of elements in this unstructured mesh (see Fig. 6) was of the order of 1600000 . Smoother shaped ground obstacles, 
used in these wind tunnel tests, have resulted in lower number of elements required to perform proper meshing, compared with the previous analyses.

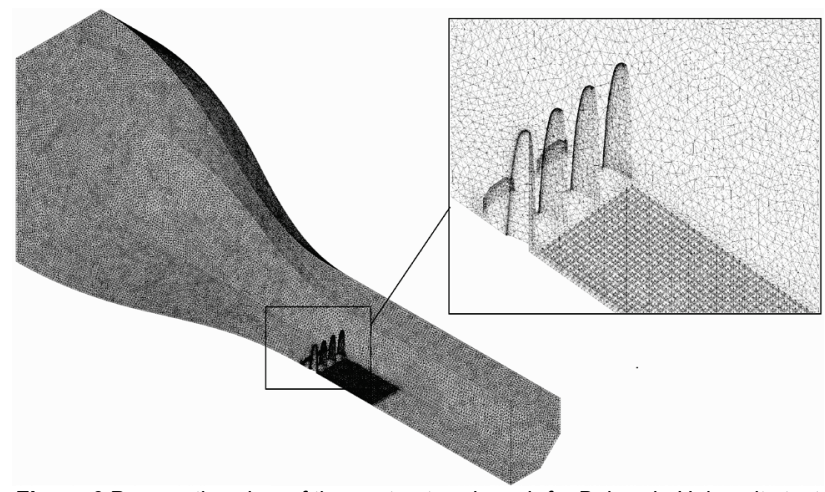

Figure 6 Perspective view of the unstructured mesh for Belgrade University test facility

Computations of the air flow within the defined control volume domain have been done by RANS equations, coupled with the SST $k-\omega$ turbulence model [19-24].

The most relevant parameters have been set as follows:

- Solver type: 3D density-based.

- Calculation type: viscous, SST $k$ - $\omega$, including curvature correction and production limiter.

- Working fluid: ideal gas - air, Sutherland law by three coefficient methods for viscosity modeling.

- Boundary conditions: inlet and outlet data are taken from [17] and [18].

- Calculation: flow - subsonic, Full Multi-Grid solution initialization, active solution steering, automatic optimization of Courant number for the achieved convergence level, etc.

It was considered that the solutions have achieved convergence when the outlet mass flow rate solution monitor remained steady (taking into account the relevant number of digits for a sufficient number of consecutive iterations, and actual number depended on a particular case).

\section{$5 \quad$ RESULTS AND DISCUSSION}

The two sets of results obtained by CFD simulations of the ABL have been compared with the appropriate experimental data in order to cover a wide range of subsonic speeds: $1-4 \mathrm{~m} / \mathrm{s}$ in the Assuit University investigations, and $45 \mathrm{~m} / \mathrm{s}$ in the Belgrade University wind tunnel. The previously described computation methodology had been established taking into account a vast number of trial calculations, after which the obtained results, qualitatively and quantitatively as well, have shown good agreements with the relevant wind tunnel test results.

First calculations were performed for the wind tunnel at the Assuit University, corresponding to the test section velocities established at fan RPM numbers of 500, 1000 , and 1440, applied in actual measurements. In the test chamber with the cross section of $1 \times 1 \mathrm{~m}$, at $1440 \mathrm{rpm}$, maximum flow rate of about $4 \mathrm{~m}^{3} / \mathrm{s}$ has been achieved, with the corresponding speed of the order of $4 \mathrm{~m} / \mathrm{s}$.
Fig. 7, obtained in Fluent, shows the velocity distributions in the plane of symmetry for the first case, where only spires were used for ABL simulations. This flow parameter has been selected for qualitative insights, because it clearly shows the flow field domains behind the spires.

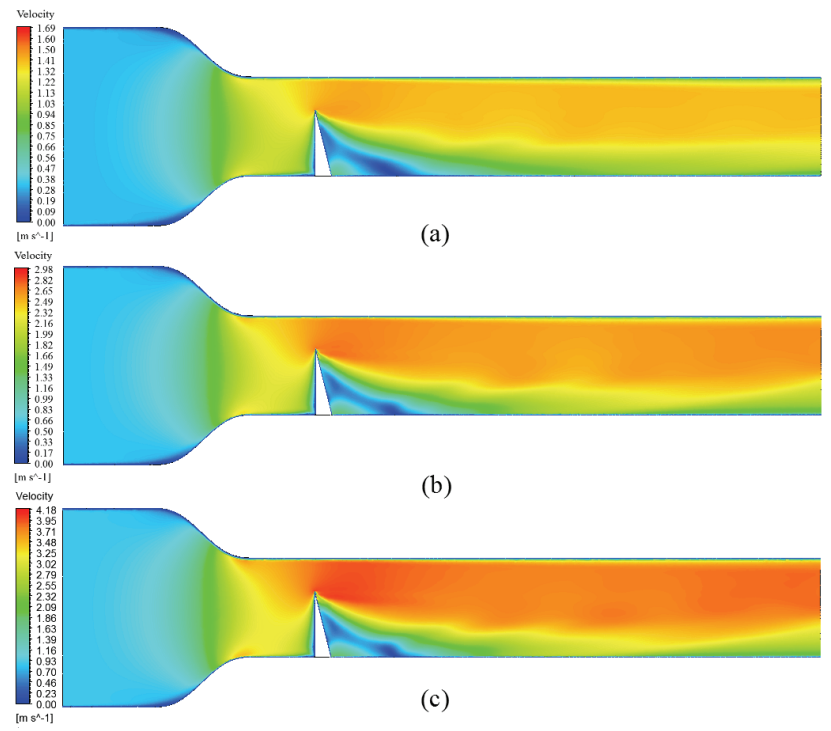

Figure 7 Contours of velocity magnitude for the case when only spires were used as obstacles, for three different fan RPM numbers of 500, 1000 and 1440, respectively (Assuit University)

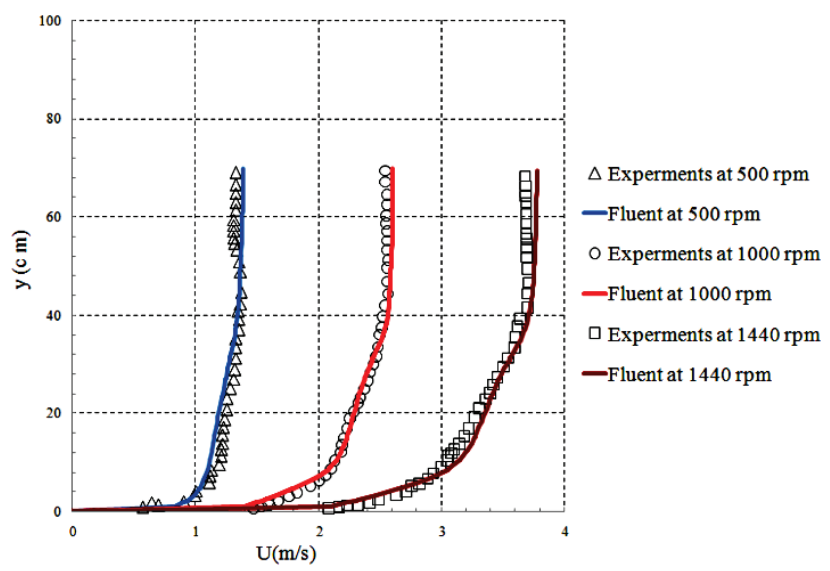

Figure 8 Vertical velocity profiles for different fan speeds; case when only spires were used as obstacles (Assuit University)

Fig. 8 shows the comparison between the vertical velocity distributions calculated by the CFD model, and the velocity profiles obtained in tunnel for three fan RPM numbers at the inlet of the test section (i.e. at $3.6 \mathrm{~m}$ distance from the entrance of the boundary layer development chamber, as shown in Fig. 3). The velocity profiles show fair agreements over the complete profile heights for all three fan RPM cases, excluding in a narrow domain above the lower wall. In real wind tunnel, even when no roughness cubes are used, the tunnel walls have their own natural roughness, which has not been mentioned in the available references. Because of that, the CFD analyses have been done assuming a smooth wall, rather than guessing what the actual roughness of the wall might be. This assumption has caused that, at low analyzed flow velocities, certain small discrepancies between the experimental and computed values in the vicinity of the wall can be noticed. 
Fig. 9 presents the contours of the velocity magnitude in the plane of symmetry for the second case, where both spires and roughness cubes had been used during the experiment. This way, the roughness elements simulate "smaller" earth surface roughnesses, such as soil condition, slopes, plants, topography, etc., in order to include their influence on the development of the atmospheric boundary layer as well.
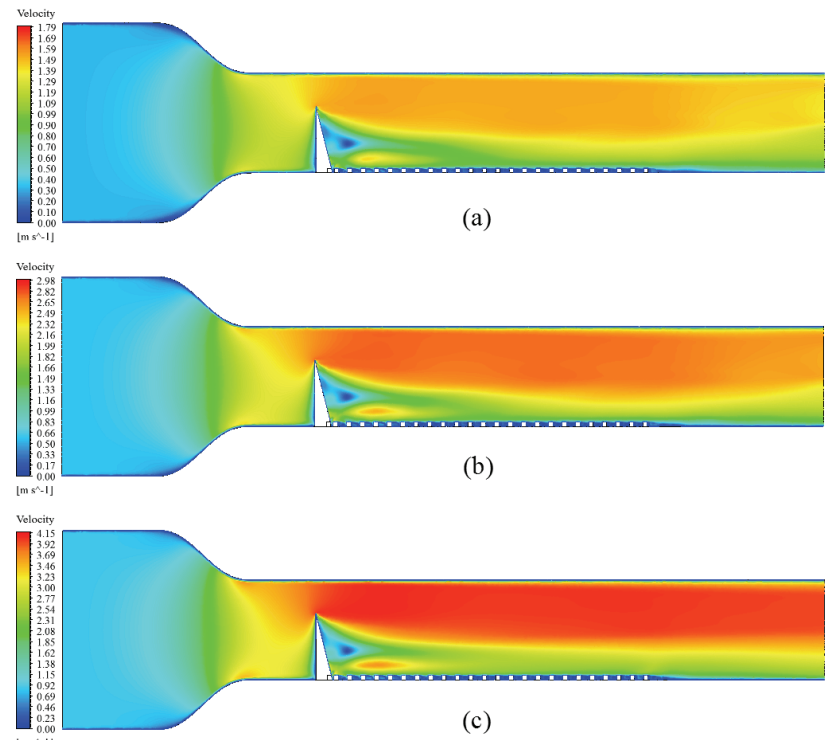

Figure 9 Contours of velocity magnitude for the case when spires and roughness cubes were used as obstacles, for three different fan RPM numbers of 500, 1000 and 1440, respectively (Assuit University)

Fig. 10 shows the vertical distribution of experimental velocity magnitudes at the test section inlet, compared with the obtained CFD results. In this case, the calculated and experimental velocity profiles coincide very well across the whole relevant vertical domain, for all three fan RPM numbers.

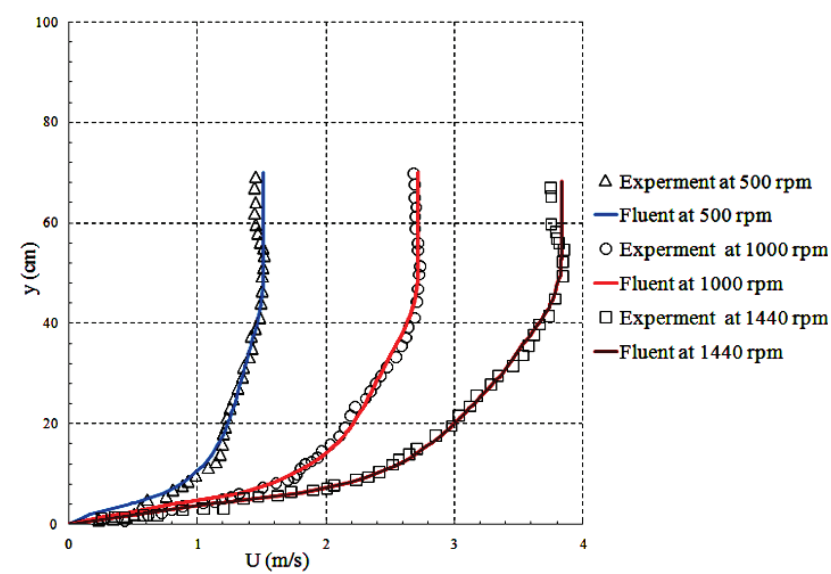

Figure 10 Vertical velocity profiles for different fan speeds; case when spires and roughness cubes were used as obstacles (Assuit University)

Fig. 11 (b) shows that the spire wakes are noticeable to the distance of about $1 \mathrm{~m}$ from the boundary layer development chamber inlet, at the fan speed of $1000 \mathrm{rpm}$. The wakes and the turbulence generated by the roughness cubes merge, and generate a dense and quite homogeneous boundary layer in the vicinity of the floor as the flow continues down the chamber. In previous case (Fig. 11 (a)), when roughness cubes were not implemented, the spire wakes protrude through a much larger distance downstream, and generate less uniform boundary layer. This part of the CFD analysis has confirmed the necessity of applying a proper combination of spires and roughness cubes, in order to achieve higher quality of the simulated atmospheric boundary layer inside the test section, where the appropriate objects (models of buildings, bridges, etc.) could be placed, in order to investigate the wind influence on them.

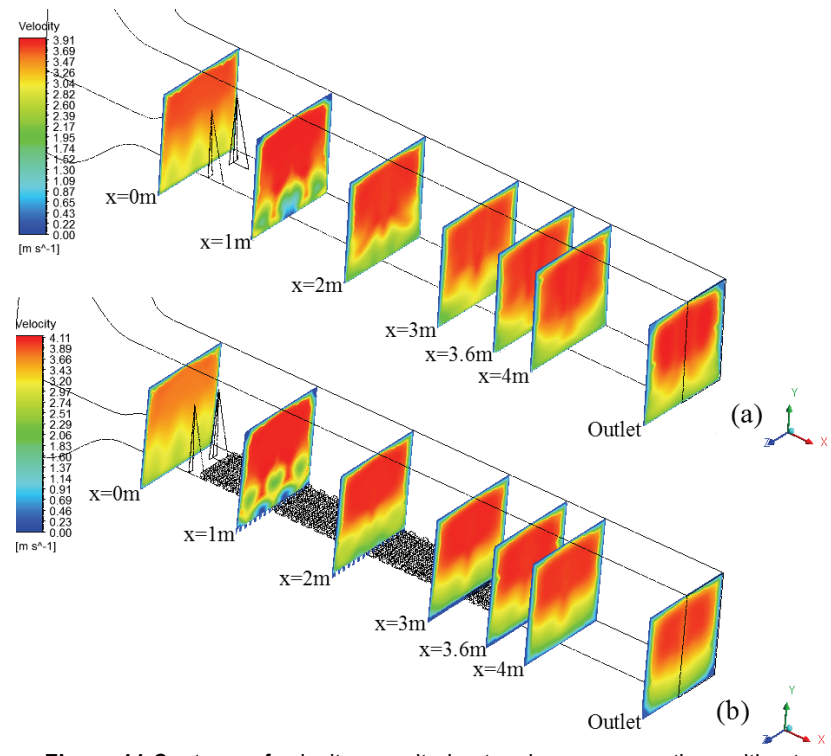

Figure 11 Contours of velocity magnitude at various cross sections without (above), and with the surface roughness elements, at Assuit University wind tunnel

After verifying the adopted calculation model on low speed flows obtained at the Assuit University, the next step was CFD modeling of practically ten times higher speed flow, used in wind tunnel tests at the Belgrade University [18], for the simulations of the ABL.

Fig. 12 shows the velocity distributions in the plane of symmetry for the combination of flat barriers, semielliptical spires and arrays of small pyramids used at the Belgrade University wind tunnel, at the speed of $45 \mathrm{~m} / \mathrm{s}$.

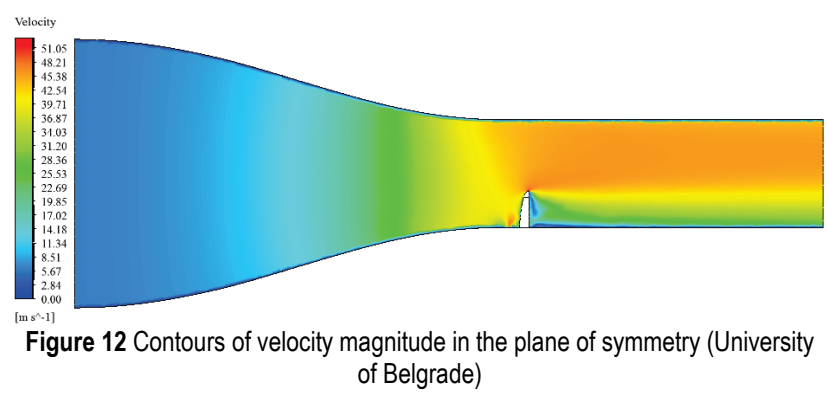

Fig. 13 presents experimental and calculated values of the relative velocity (velocity at the half distance along the actual test section, divided by velocity at the inlet of test section, denoted as $U / U_{0}$ in [18]) along the relative height (vertical distance from the bottom wall, divided by the height of spires $y / h_{s}$ ). Results obtained from numerical calculations for this test also show quite fair compliance with the wind tunnel measurements, for the operational design applications. 


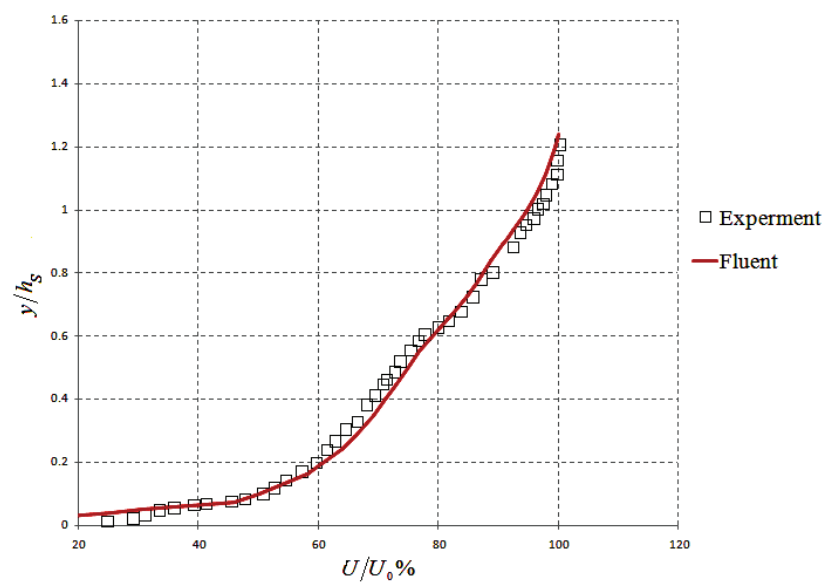

Figure 13 Experimental and calculated relative velocity distributions (University of Belgrade)

The contours of velocity magnitude at several cross sections along the test chamber are presented in Fig. 14. The wakes generated by the barriers and semi-elliptical spires are clearly seen at the position $x=1.5 \mathrm{~m}$ from the test section inlet, over the surface roughness elements. On the other hand, from $x=3 \mathrm{~m}$ and all the way to the test section outlet, the simulated atmospheric boundary layer domain is obviously quite homogenous, confirming that the experimental test setup has been properly established.

After the calculation model has been proven as reliable and accurate for practical engineering purposes through the comparisons with the existing experimental data, it can be used as a supplement tool to obtain additional information about the test conditions, parameters, etc. that were not actually measured or recorded.

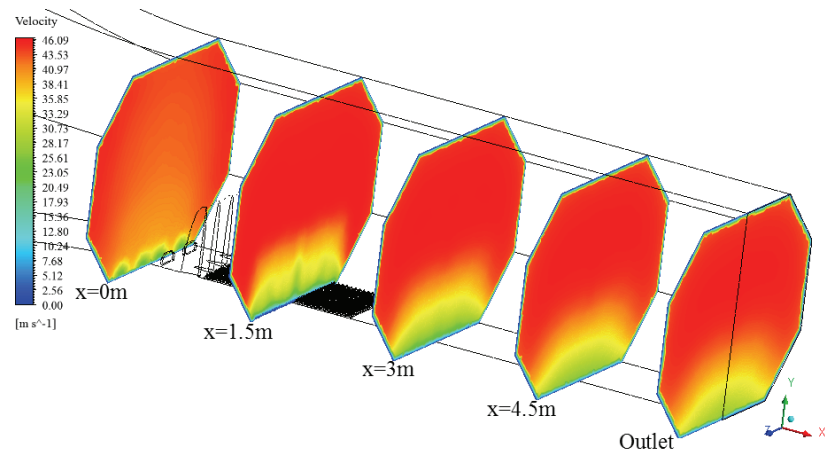

Figure 14 Contours of velocity magnitude at different positions inside the test section (University of Belgrade)

Two illustrations are shown in Figs. 15 and 16. In Fig. 15 the contours of eddy viscosity obtained by the CFD analysis for the test section at Assuit University are shown. For the case of spires only, the domain of large eddy viscosities emerges after the spires and near the bottom wall, and then it fades out along the development section. On the other hand, when spires were used together with the roughness cubes, the eddy viscosity quite uniformly propagates downstream, and its higher intensity domain is noticeable at the mid height of the spires, while bottom domain is quite uniformly mixed. Such detailed flow patterns were not captured during the actual tests.

Principally the same applies for the eddy viscosity spatial contours of Belgrade University wind tunnel. Applied combination of experimental obstacles (flat plates, spires and surface roughness) generate very uniform wake, which simulates ABL generated by trees, houses, ground roughnesses, etc. It should also be compared with the freedeveloped turbulent boundary layer on the upper wall, which can be clearly depicted in Figs. 15 and 16.
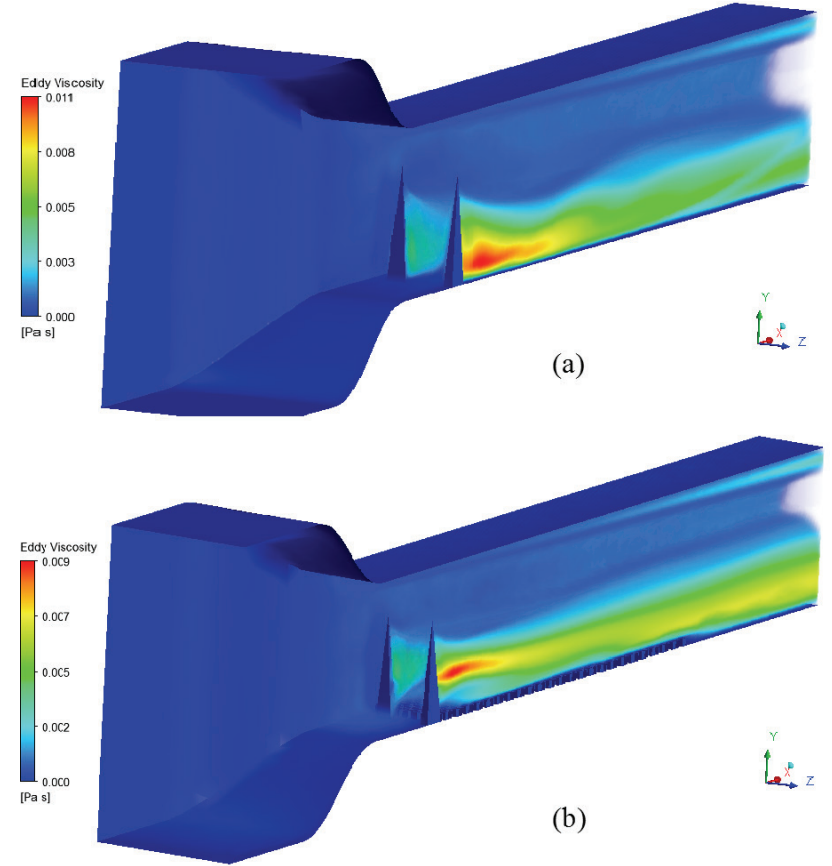

Figure 15 Calculated eddy viscosity in wind tunnel for the fan speed of 1000 rpm; (a) spires only, and (b) spires and surface roughness elements (Assuit University)

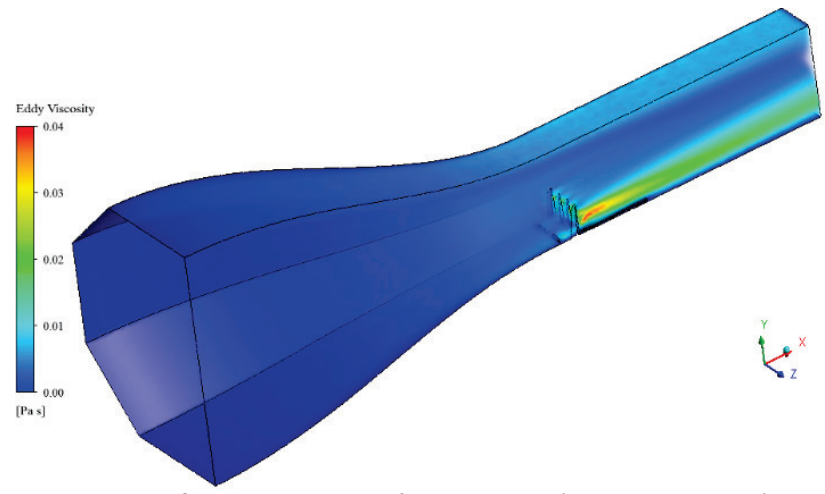

Figure 16 Calculated contours of eddy viscosity (Belgrade University)

Very important advantage of the contemporary CFD calculation models is their capability to analyze a wide variety of devices and shapes that can be used in wind tunnels for proper ABL simulation. Namely, instead of performing expensive wind tunnel tests and measurements to determine the suitability of different kinds of obstacles to generate proper and homogenous $\mathrm{ABL}$ model, the virtual CFD tunnel can be used, at much lower cost, for the same purpose. Once verified by CFD analyses, experimental setup can be arranged, and used for the tests of the wind influence on different kinds of ground objects like buildings, bridges, wind turbines, etc. (measuring pressure distributions and/or forces acting on them), but taking also into account the atmospheric boundary layer influence, generated by the surrounding topology and obstacles. Furthermore, the CFD runs with the included test objects could also be done simultaneously with the wind 
tunnel tests. After verifying computational results using the obtained experimental data, the CFD analyses can readily be applied to replace a remarkable number of wind tunnel experiments, and this way reduce the total expenses of the given project.

\section{CONCLUSION}

Investigations of the wind influence on different kinds of ground objects must always include proper analysis of the atmospheric boundary layer, or ABL development around them, influenced by the surrounding earth surface topology and obstacles. For that purpose, subsonic wind tunnels have been widely used for many years. Before performing measurements on the test objects, thorough investigations considering the appropriate simulations of the ABL must be made.

In this work, the authors have applied contemporary CFD tools in order to adequately model the flow patterns in wind tunnels during such kind of tests. The primary aim was to establish an accurate calculation algorithm and setups that could be used in wide speed range considering the real life conditions, with the capability to adequately simulate the influence of typical obstacle shapes used to generate the $\mathrm{ABL}$ velocity profiles.

For the verifications of numerical calculations, experimental results from wind tunnels, at Assiut University and University of Belgrade, were applied. In Assiut tunnel, very low velocities were applied, ranging from $1 \mathrm{~m} / \mathrm{s}$ to $4 \mathrm{~m} / \mathrm{s}$, while at Belgrade University, velocity of $45 \mathrm{~m} / \mathrm{s}$ (or $162 \mathrm{~km} / \mathrm{h}$, corresponding to a severe storm) was established. After a vast series of computer test runs, the computational algorithm presented in this paper, concerning meshing methodology and computational parameters, based on the RANS equations with SST $k$ - $\omega$ turbulent model, has been established. For both cases, the relevant wind tunnel sections were modeled by control volumes in 1:1 scale.

Results obtained by this calculation algorithm were compared with the wind tunnel measurements of the velocity profiles within the modeled ABL. Considering the Assiut University wind tunnel, six available velocity profiles were used for the quantitative verifications corresponding to very low wind speed ABL profiles, three with spires only, and three with spires and surface roughness elements. In case of Belgrade University tests, a velocity profile generated by spires and surface roughness, corresponding to a stormy wind ABL, was used. For all these cases, good agreements between the calculated and experimental velocity profiles for practical engineering applications have been achieved, indicating that the same established computational algorithm can readily be used for a wide wind speed range analyses. In the sense of qualitative analyses, CFD computations have provided detailed insight in the flow-fields within the simulated ABL's. Calculated three-dimensional contours of velocity magnitude and eddy viscosity profiles have shown that in both wind tunnels, when spires and surface roughness elements were simultaneously applied, good vertical and lateral flow homogeneity had been established in the wind tunnel test sections where velocity profiles were measured.

By this, the presented computational model has been verified in the sense of its ability to substitute a vast portion of much more expensive wind tunnel test runs, during the preparation of adequate experimental obstacle arrangements for proper ABL modeling, for speeds ranging from a light breeze values to about $160 \mathrm{~km} / \mathrm{h}$. Such computational model can also be easily calibrated and used to reduce the amount of experimental working hours during the tests of the wind and the corresponding ABL influence on the ground structures, such as wind turbines, buildings, bridges, etc.

\section{REFERENCES}

[1] Yassin, M. F. (2004). Study on Pollutant Dispersion within Urban Area under Changes of Atmospheric Stability and Wind Direction. PhD Thesis, Graduate School of Faculty of Engineering, University of Tokyo, Japan, Environmental Engineering.

[2] Cermak, J. E. (2003). Wind-Tunnel Development and Trends in Applications to Civil Engineering. J. of Wind Engineering and Industrial Aerodynamics, 91(3), 355-370. https://doi.org/10.1016/S0167-6105(02)00396-3

[3] Gorlé, C., Beeck, J. V., Rambaud, P., \& Tendeloo, G. V. (2009). CFD modelling of small particle dispersion: The influence of the turbulence kinetic energy in the atmospheric boundary layer. Atmospheric Environment, 43, 673-681. https://doi.org/10.1016/j.atmosenv.2008.09.060

[4] Leitl, B., Kastner-Klein, P., Rau, M., \& Meroney, R. N. (1997). Concentration and flow distributions in the vicinity of u-shaped buildings: wind-tunnel and computational data. $J$. of Wind Eng. and Ind. Aerody. 67-68, 745-755. https://doi.org/10.1016/S0167-6105(97)00115-3

[5] Chang, C. \& Meroney, R. (2003). Concentration and flow distributions in urban street canyons: wind tunnel and computational data. J. of Wind Eng. and Ind. Aerody. 91, 1141-1154. https://doi.org/10.1016/S0167-6105(03)00056-4

[6] Yang, W., Jin, X., Jin, H., Gu, M., \& Chen, S. (2007). Application of new inflow boundary conditions for modeling equilibrium atmosphere boundary layer in rans-based turbulence models. Proceedings of International Conference on Wind Engineering / Australia, 591-598.

[7] Pieterse, J. E. (2013). CFD Investigation of the Atmospheric Boundary Layer under Different Thermal Stability Conditions. MSc Thesis, Stellenbosch University. https://doi.org/10.1016/j.jweia.2013.07.014

[8] Alinot, C. \& Masson, C. (2002). Aerodynamic Simulations of Wind Turbines Operating in Atmospheric Boundary Layer with Various Thermal Stratifications. ASME Conference Proceedings / Reno, Nevada, USA, 206-215.

[9] Blocken, B., Carmeliet, J., \& Stathopoulos, T. (2007). CFD Evaluation of Wind Speed Conditions in Passages Between Parallel Buildings - Effect of Wall-Function Roughness Modifications for the Atmospheric Boundary Layer Flow. Journal of Wind Engineering and Industrial Aerodynamics, 95(9), 941-962. https://doi.org/10.1016/j.jweia.2007.01.013

[10] Blocken, B., Stathopoulos, T., \& Carmeliet, J. (2007). CFD Simulation of the Atmospheric Boundary Layer: Wall Function Problems. Atmospheric Environment, 41(2), 238252. https://doi.org/10.1016/j.atmosenv.2006.08.019

[11] Hargreaves, D. \& Wright, N. (2007). On the Use of the k-E Model in Commercial CFD Software to Model the Neutral Atmospheric Boundary Layer. Journal of Wind Engineering and Industrial Aerodynamics, 95(5), 355-369. https://doi.org/10.1016/j.jweia.2006.08.002

[12] Fang, P., Gu M., Tan, J., Zhao, B., \& Shao, D. (2009). Modeling the Neutral Atmospheric Boundary Layer Based on the Standard k- $\varepsilon$ Turbulent Model: Modified Wall Function. The Seventh Asia-Pacific Conference on Wind Engineering / Taipei, Taiwan. 
[13] ANSYS, Inc. ANSYS FLUENT. (2015). Release 16.0: Installation and User's Guide. SAS IP, Inc.

[14] Shojaee, S. M. N., Uzol, O., \& Kurc, Ö. (2014). Atmospheric boundary layer simulation in a short wind tunnel. Int. $J$. Environ. Sci. Technol, 11, 59-68. https://doi.org/10.1007/s13762-013-0371-4

[15] Rados, K. G., Prospathopoulos, J. M., Stefanatos, N. C., Politis, E. S., Chaviaropoulos, P. K., \& Zervos, A. (2009). CFD modeling issues of wind turbine wakes under stable atmospheric conditions. EWEC Proceedings, Marseille.

[16] Yang, W., Quan, Y., Jin, X., Tamura, Y., \& Gu, M. (2008). Influences of Equilibrium Atmosphere Boundary Layer and Turbulence Parameter on Wind Loads of Low-rise Buildings. J. of Wind Eng. and Ind. Aerody. 96(10), 20802092. https://doi.org/10.1016/j.jweia.2008.02.014

[17] Al-Nehari, H., Abdel-Rahman, A. K., Nassib, A., \& Shafey, H. M. (2010). Design and Construction of a Wind Tunnel for Environmental Flow Studies. Journal of Engineering Sciences, Assiut University, 38(1), 177-193.

[18] Stefanović, Z. \& Pešić, S. (1992). Simulation of Atmospheric Boundary Layer in Laboratory Conditions (in Serbian). Proceedings: Contemporary Problems in Fluid Mechanics / University of Belgrade, Serbia.

[19] ANSYS FLUENT 16.0. (2015). Theory Guide, ANSYS, Inc., Canonsburg, PA.

[20] Menter, F. R. (1993). Zonal Two Equation $k-\omega$ Turbulence Models for Aerodynamic Flows. AlAA paper 93-2906, $24^{\text {th }}$ Fluid Dynamics Conference / Orlando, Florida, 1-21. https://doi.org/10.2514/6.1993-2906

[21] Leifsson, L., Koziel, S., Andrason, F., Magnusson, K., \& Gylfason, A. (2012). Numerical Optimization and Experimental Validation of a Low - Speed Wind Tunnel Contraction. Procedia Computer Science, 9, 822-831. https://doi.org/10.1016/j.procs.2012.04.088

[22] Yassen, Y. E. \& Abdelhamed, A. S. (2015). CFD Modeling of the Atmospheric Boundary Layer in Short Test Section Wind Tunnel. American Journal of Aerospace Engineering, 2(1), 38-46. https://doi.org/10.11648/j.ajae.s.2015020101.14

[23] Karim, M. M., Rahman, M. M., \& Alim, M. A. (2011). Performance of SST k- $\omega$ Turbulence Model for Computation of Viscous Drag of Axisymmetric Underwater Bodies. IJE Transactions B: Applications, 24(2), 139-146.

[24] Wilcox, C. D. (2006). Turbulence Modeling for CFD. $3^{\text {rd }}$ ed. DCW Industries, California.

\section{Contact information:}

\section{Ahmed ABUBAKER, PhD Student}

University of Belgrade,

Faculty of Mechanical Engineering,

Kraljice Marije 16, 11120 Belgrade, Serbia

E-mail: irhyim2009@gmail.com

dr. sc. Ivan KOSTIĆ, Full Professor

University of Belgrade,

Faculty of Mechanical Engineering,

Kraljice Marije 16, 11120 Belgrade, Serbia

E-mail: ikostic@mas.bg.ac.rs

dr. sc. Olivera KOSTIĆ, Assistant Professor

University of Belgrade,

Faculty of Mechanical Engineering

Kraljice Marije 16, 11120 Belgrade, Serbia

E-mail: okostic@mas.bg.ac.rs

dr. sc. Zoran STEFANOVIĆ, Full Professor, retired

University of Belgrade,

Faculty of Mechanical Engineering

Kraljice Marije 16,11120 Belgrade, Serbia

E-mail: zstefanovic@mas.bg.ac.rs 